\title{
Medicines to Enhance Self-Consciousness, Mindfulness and Healthy Ageing?
}

\author{
Pierre A Guertin* \\ Department of Psychiatry and Neurosciences, Canada \\ *Corresponding author: Pierre A Guertin, Department of Psychiatry and Neurosciences, Canada \\ Submission: 眥 December 03, 2018; Published: 望笽January 09, 2019
}

\begin{abstract}
Ageing is well-known to progressively lead to a general loss of physical and neurological functions. Specific health problems such as Parkinson's Disease, dementia, memory loss, cerebrovascular problems and Alzheimer's Disease are also associated with ageing. Consequently, average levels of self-consciousness and mindfulness expressed by older individuals may be expected to decrease. This said, increasing evidence suggests that meditative approaches can promote healthy ageing. Specific medicines could perhaps be used to further improve healthy ageing by preventing or reversing partially self-consciousness and mindfulness losses? This short article summarizes briefly some of the tools and approaches that could perhaps be explored to improve concentration, memory, awareness and health in elderly with or without ageing-related diseases.
\end{abstract}

Keywords: Aging; Meditation; Mind; Soul; Awareness; Drugs; Serotonin; Glutamate; N-Methyl-D-Aspartate

\section{Introduction}

\section{Definitions of self-consciousness, self-awareness and mindfulness}

Some people have defined consciousness as a specific level of awareness whereas others consider consciousness more globally as the mental capacity of any living organism of sensing and responding to its world [1,2]. Above and beyond, there is self-consciousness or self-awareness that can be defined as the ability of 'being aware of being conscious' [3]. Evans, Baer and Segerstrom or KabatZinn have come up with a comparable definition of mindfulness - a present-centered and non-reactive type of self-awareness or self-consciousness requiring a higher level of focus on the present moment without any judgment [4,5]. Self-consciousness, selfawareness and mindfulness would enable someone to stay "above" the particular content of thoughts, emotions, or imaginations.

\section{Roles of specific brain areas}

If we accept that these functions or abilities are essentially of biological origin (unlike what most religions claim), the question is: where do they lie in the brain? Dr. Penfield from McGill University found a few decades ago in awake patients with epilepsy that electrical stimulation of small distinct brain areas can trigger highly specific memories or feelings - e.g., the smell of burnt toasts or numbness in their fingers. This breakthrough has brought psychical phenomena into the field of neurophysiology [6]. Since then, many neuroscientists have examined closer the role of various neurological mechanisms in mediating consciousness and/or selfconsciousness-synchronous oscillation of neurons, n-methyl-d- aspartate (NMDA)-mediated transient neural assemblies, patterns of cortical activation modulated by the thalamus, reentrant cortical

loops, continuous action prediction assessment loops involving the frontal and midbrain areas, and somatosensory processes based in the frontal-limbic or periaqueductal gray area [7-10].

\section{Levels of self-consciousness decrease over time}

Aging is associated with changes in brain size (e.g. 5\% less every decade after 40-year-old), vasculature, cognition, neurotransmitters (e.g. dopamine and serotonin levels decrease by $10 \%$ every decade), and NMDA-dependent memory-related mechanisms [11]. When some of these changes reach pathological levels, aging-related neurological diseases occur or become diagnosable - e.g., Parkinson's Disease, dementia, confusion and memory loss, cerebrovascular problems and Alzheimer's Disease [12]. Given that self-consciousness, self-awareness or mindfulness depend upon one or several specific brain areas affected normally by aging, it is reasonable to consider that they are, in general, negatively altered in elderly although this has never been demonstrated experimentally.

\section{Training those mental abilities can improve brain} functions and health

Mindfulness Based Cognitive Therapy (MBCT) and Mindfulness Based Stress Reduction (MBSR) approaches have been reported to enhance attention, memory and executive motor function although induced-effect levels may depend on the approach used [13-15]. Effects on general health (e.g., cardiovascular function, blood 
pressure) have also been reported with some of these approaches (e.g., transcendental meditation [16,17]). It remains unclear though if increased memory or attention often found in those studies means also that self-consciousness or self-awareness are equally enhanced - the validity of those correlates for assessing and measuring selfconsciousness and mindfulness has not been established clearly.

\section{Combining meditative approaches and medicines could perhaps further increase self-consciousness, self- awareness and mindfulness and/or their effects on health}

It is already known that some psychedelic drugs such as ketamine, mescaline, lysergic acid diethylamide (LSD), Salvia diviner, and psilocybin can increase brain signal diversity - a measure of complex neural activity and consciousness [18]. The enhanced release of some endogenous neurochemicals (e.g., serotonin/5-HT, dopamine, noradrenaline, etc.) stimulated by vagal nerve stimulation has been shown to restore consciousness in a comatose person [19]. It is then not unreasonable to believe that administration of highly selective ligands (e.g. 5-HT2A receptor agonists) capable to mimic partially the actions of some of those neurochemicals (e.g. 5-HT) can perhaps elicit comparable or superior effects on those higher functions while inducing fewer side-effects. Targeting directly specific subcellular target(s) may be another strategy for highly selective effects. For instance, the transmembrane 5-HT2A receptor is known to couple to the

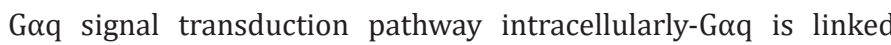
to downstream effector pathways including $\mathrm{G} \alpha \mathrm{q}$ stimulates phospholipase C activity, which subsequently promotes the release of diacylglycerol and inositol triphosphate, which in turn stimulate protein kinase $\mathrm{C}$ activity and calcium release. Any of those downstream intracellular mechanisms may constitute new therapeutic targets for greater specificity, superior efficacy and lesser safety concerns. These promising avenues remain to be explored.

\section{Conclusion}

If some meditative approaches can be used to increase memory and concentration, then medicines known to enhance mental activity in specific areas associated with self-consciousness, self-awareness and mindfulness shall normally further enhance those mental functions. Along the same idea, novel combinatorial therapeutic approaches using compounds (e.g. new selective 5-HT2A receptor agonists, 5-HT1A receptor agonists, 5-HT7 receptor agonists, dopapamine D2-like receptor agonists, NMDA receptor antagonists, etc), if safer than psychedelic drugs, could perhaps be developed to compensate ageing-related functional losses while improving meditation-induced effects on self-consciousness, healthy aging, and longevity [14,20-27]. Non-hallucinogenic LSD analogs (e.g. BOL148) or 5-HT2A agonists such as TCB-2, jimscaline (vegetal origin) and $25 \mathrm{CN}-\mathrm{NBOH}$ are examples of new highly selective compounds in preclinical development for other therapeutic indications (e.g. memory problems, cluster headaches) that may also potentially increase the effects of meditative approaches in elderly suffering or not of ageing-related diseases [28]. Identifying strategies (e.g. highly selective ligands, downstream targets, selective drug delivery systems, lower doses, specific drug combinations, etc.) aimed at increasing benefits on brain functions and health of some of these compounds while reducing their undesirable hallucinogenic effects is a challenge that absolutely needs to be addressed.

\section{References}

1. Robert Van G (2004) Consciousness. Stanford Encyclopedia of Philosophy.

2. Armstrong D (1981) What is consciousness? In the Nature of Mind. Ithaca, Cornell University Press, New York, USA.

3. Carruthers P (2000) Phenomenal consciousness. Cambridge: Cambridge University Press, UK.

4. Evans DR, Eisenlohr Moul TA, Button DF, Baer RA, Segerstrom SC, et al. (2014) Self-regulatory deficits associated with unpracticed mindfulness strategies for coping with acute pain. J Appl Soc Psychol 44(1): 23-30.

5. Kabat Zinn J (2005) Bringing mindfulness to medicine: An interview with Jon Kabat-Zinn, PhD. Interview by Karolyn Gazella. Adv Mind Body Med 21(2): 22-27.

6. Blum A (2011) A bedside conversation with Wilder Penfield. CMAJ 183(7): 745-746.

7. Llinas R (2001) I of the vortex: From neurons to self. Cambridge, MIT Press, USA.

8. Edelman G (1989) The Remembered Present: A Biological Theory of Consciousness. Basic Books, New York, USA.

9. Gray J (1995) The contents of consciousness: A neuropsychological conjecture. Behavior and Brain Sciences 18(4): 659-722.

10. Damasio A (1999) The Feeling of what happens: Body and emotion in the making of consciousness. Harcourt, New York, USA

11. Leo H, Rognmo O, Salin B, Wisloff U (2013) Aerobic capacity reference data in 3816 healthy men and women $20-90$ years. PloS ONE 8(5): e64319.

12. Peters R (2006) Ageing and the brain. Postgrad Med J 82(964): 84-88.

13. Upadhyay RK (2015) Emerging risk biomarkers in cardiovascular diseases and disorders. J Lipids: 971453.

14. Marciniak R, Sheardova K, Cermáková $P$, Hudeček D, Sumec R, et al. (2014) Effect of meditation on cognitive functions in context of aging and neurodegenerative diseases. Front Behav Neurosci 8: 17.

15. Lao SA, Kissane D, Meadows G (2016) Conscious Cognitive effects of MBSR/MBCT: A systematic review of neuropsychological outcomes. Cogn 45: 109-123.

16. Gupta SK, Sawhney RC, Rai L, Chavan VD, Dani S, et al. (2011) Regression of coronary atherosclerosis through healthy lifestyle in coronary artery disease patients--Mount Abu Open Heart Trial. Indian Heart J 63(5): 461-469.

17. Ponte Márquez PH, Feliu Soler A, Solé Villa MJ, Matas Pericas L, Filella Agullo D, et al. (2018) Benefits of mindfulness meditation in reducing blood pressure and stress in patients with arterial hypertension. J Hum Hypertens.

18. Michael M Schartner, Robin Carhart Harris L, Adam B Barrett, Anil K Seth, Muthukumaraswamy, et al. (2017) Increased spontaneous MEG signal diversity for psychoactive doses of ketamine, LSD and psilocybin. Scientific Reports 7: 46421.

19. Corazzol M, Leo G, Lefevre A, Diana G, Tell L, et al. (2017) Restoring consciousness with vagus. nerve stimulation. Curr Biol. 27(18): R994-R996. 
20. Acevedo BP, Pospos S, Lavretsky H (2016) The Neural Mechanisms of Meditative Practices: Novel Approaches for Healthy Aging. Curr Behav Neurosci Rep 3(4): 328-339.

21. Pagnoni G, Cekic M (2007) Age effects on gray matter volume and attentional performance in Zen meditation. Neurobiol. Aging 28(10): 16231627.

22. Alexander CN, Langer EJ, Newman RI, Chandler HM, Davies JL, et al. (1989) Transcendental meditation, mindfulness, and longevity: an experimental study with the elderly. J Pers Soc Psychol 57(6): 950-964.

23. Wong WP, Coles J, Chambers R, Wu DB, Hassed C, et al. (2017) The effects of mindfulness on older adults with mild cognitive impairment. J Alzheimers Dis Rep 1(1): 181-193.

24. López Giménez JF, González Maeso J (2018) Hallucinogens and serotonin 5-HT2A receptor-mediated signaling pathways. Curr Top Behav Neurosci 36: $45-73$
25. Vollenweider FX, Geyer MA (2001) A systems model of altered consciousness: Integrating natural and drug-induced psychoses. Brain Res Bull 56(5): 495-507.

26. De Gregorio D, Posa L, Ochoa Sanchez R, McLaughlin R, Maione S, et al (2016) The hallucinogen d-lysergic diethylamide (LSD) decreases dopamine firing activity through 5- HT1A, D2 and TAAR1 receptors. Pharmacol Res 113(Pt A): 81-91.

27. De Gregorio D, Enns JP, Nuñez NA, Posa L, Gobbi G, et al. (2018) D-Lysergic acid diethylamide, psilocybin, and other classic hallucinogens: Mechanism of action and potential therapeutic applications in mood disorders. Prog Brain Res 242: 69-96.

28. Zhang G, Ásgeirsdóttir HN, Cohen SJ, Munchow AH, Barrera MP, et al. (2013) Stimulation of serotonin 2A receptors facilitates consolidation and extinction of fear memory in C57BL/6J mice. Neuropharmacology 64: 403-413. (c) (i) Creative Commons Attribution 4.0

For possible submissions Click Here
Submit Article

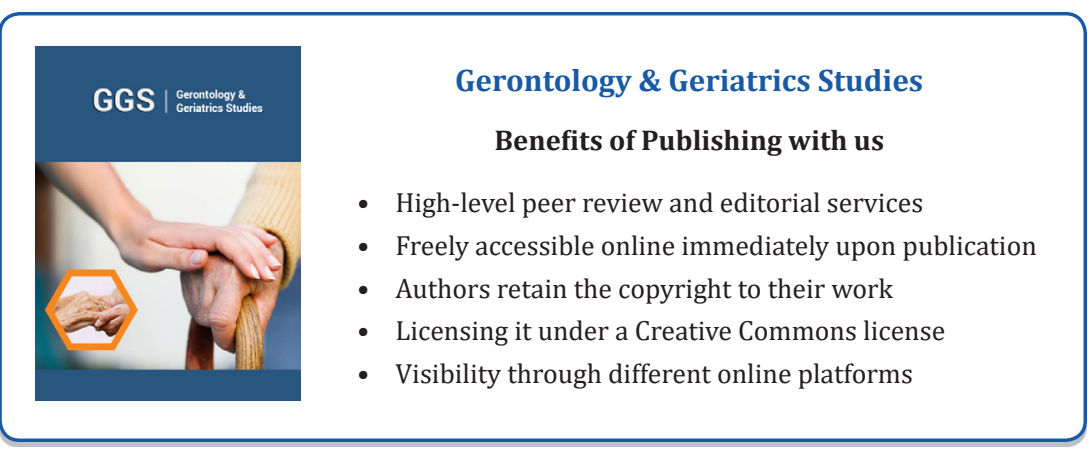

